\title{
Mineral Base Oil Recovery from Waste Lubricant Grease
}

\author{
Daka Makangila Misozi ${ }^{1, a}{ }^{*}$, Mwaba Victor ${ }^{1, \mathrm{~b}}$, Mvula Ebelia ${ }^{1, \mathrm{c}}$ Chanda Phiri Tina ${ }^{1, \mathrm{~d}}$ \\ ${ }^{1}$ Copperbelt University, P.O. Box 21962, Kitwe, Zambia \\ a*Misozi.Makangila@cbu.ac.zm, ${ }^{\mathrm{b}}$ mwaba.isaac410@gmail.com, ${ }^{\mathrm{c}}$ ebelia.mvula@cbu.ac.zm ${ }^{\mathrm{d}}$ tina.phiri@cbu.ac.zm
}

\begin{abstract}
Lubricants play an important role in the running of automotive and related machines. They prevent wear and tear of machines through the provision of a protective film between two moving parts. With time, the performance of grease is reduced creating a problem of waste lubricant grease. This research investigated the recovery of mineral base oil from waste lubricating grease obtained from the mining industry. A base was used to flocculate the impurities and temperature was applied to degrade the waste grease. A solvent was further used to separate and purify the sludge mixture generated. The investigation achieved recovery of base oil from the waste oil sourced from a mine. Other parameters which were determined included Calorific value, viscosity and water content. Recovery of valuable base oil indicated the prospects of volume reduction of waste grease at storage facilities and possibilities of blending with other oils to enhance their fuel capacities.
\end{abstract}

Keywords: Base oil, Lubricant Grease, Recovery

\section{Introduction}

Grease is a lubricating material used in machines. Lubricating grease is used to reduce wear, tear and friction in machinery. It is a solid to semi-solid material consisting of thickening agent dispersed in a liquid lubricant such as mineral oil (petroleum oil), synthetic oil (silicone oil) or vegetable oil [1]. Large volumes of hazardous waste grease are generated from these high and heavy machinery equipments. This is as a result of foreign substances for example metal powder, chips and other grease when mixed into the lubricant grease leads to the aging, degrading and mechanical failure and reduced performance hence the need to replace the lubricant [8]. Grease disposal is a serious challenge. In most cases, these are stock pilled as shown in figure 1 .

Hazardous wastes management requires a holistic approach encompassing treatment, storage and disposal in order to ensure its reduction in pollution potential. In Zambia, the disposal of hazardous waste is governed by the Hazardous Waste Management Regulations (Statutory Instrument No. 125 of 2001). This provide for the control of hazardous waste so that the waste is managed in an environmentally sound manner through waste prevention, reduction, recycling, incineration and landfilling. The regulations further provide for control of generation, collection, storage, transportation, treatment, import, export and final disposal of hazardous waste.

Greases are made by dispensing thickening agent into carry lubricant oil. The actual lubricant can be petroleum (mineral) oil, synthetic oil or vegetable oil. Typical grease composition contains $70-95 \mathrm{wt}$. $\%$ base fluid, 3 - $30 \mathrm{wt} \%$ thickener (simple, complex and non-soap) and $0-10 \mathrm{wt} \%$ performance additives [4]. Most of lubricating oils and greases used in the most process and mine industry is mineral based. They contain a mixture of undegraded base oil and additives with high concentration of metals, 
waste oil, gums and other asphaltic compounds hence not environmentally friendly or termed as hazardous $[2,3]$.

In spite of its usefulness, grease can cause serious environmental pollutions if not properly disposed which includes groundwater, surface water and soil contamination [3]. Burning of waste grease and oils can release harmful air pollutants [4] which may include carbon monoxide, Sulphur oxides, nitrogen oxides, particulate matter and metals [5]. Because of the high volumes of waste grease generated and the lack of disposal facilities, a need to look for avenues to manage this waste is required. In response to safely reduce on material use and protection of the environment, there is need to regenerate and reuse waste lubricate [4].

This investigation was conducted in order to recover valuable base oil from mineral based grease thus reducing the amount and treating waste grease at hazardous storage facilities.

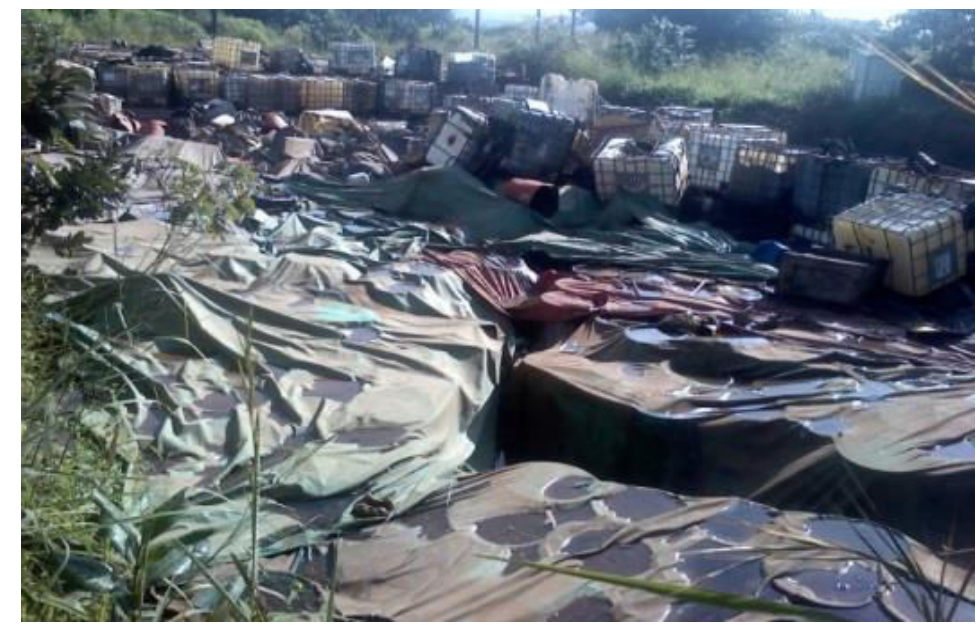

Figure 1, Hazardous dumpsite with drums of waste grease

\section{Materials and Methods}

\subsection{Materials}

Lubricating waste grease sourced from a mine, Regents used included Toluene and Potassium Hydroxide $(\mathrm{KOH})$.

\subsection{Methods}

The method used in the research was adopted from reference [11]. Three hundred grams of $15 \%$ w/w KOH solution was transferred to $1000 \mathrm{ml}$ beaker and heated to $85^{\circ} \mathrm{c}$. Homogenisation of grease was achieved with the use of $\mathrm{KOH}$ solution. The applied temperature aided in the decomposition of grease. Solubility of base oil and waste oil impurities in organic solvents is affected by temperature [6]. Studies have shown that the optimum temperature for the degradation of waste grease is $80^{\circ} \mathrm{c}$ [4]. One hundred grams of waste grease was slowly dissolved into the heated KOH solution, while 
agitating between $1200 \mathrm{rpm}$ with a high shear impeller blade for 15 minutes. A study by reference [7] has shown that oil extraction yields increases with increase in speed agitation.

The resulting mixture was allowed to settle for 10 minutes and the floating dark brown oil layer was decanted and its weight measured. The bottom layer was cooled down to $45^{\circ} \mathrm{C}$ and the resulting sludge was further treated using Toluene. Toluene was added to the sludge mixture at the mass ratio of 2:1. The mixture was stirred at $700 \mathrm{rpm}$ to ensure complete mixing and the temperature was maintained at $45^{\circ} \mathrm{C}$. Toluene was added to the mixture in order to recover any remaining oil in the sludge. Distillation of the resulting organic mixture was conducted at $110^{\circ} \mathrm{c}$, enabling the separation of the base oil from the resulting sludge. Weights of the recovered base oil were recorded. The resulting solutions when $\mathrm{KOH}$ to the waste grease and recovered oil resultant organic mixture is shown in figure 2 . The process flow chart for one of the runs performed is shown in figure 3. Reference [7] indicates the calculation of oil recovered using equation 1.

$$
\text { Extracted Oil Yield }(\%)=\frac{\text { Oil Extracted }(\mathrm{g})}{\text { Waste Grease Feed }(\mathrm{g})} \times 100 \ldots \ldots \ldots \ldots \ldots \ldots \text { equation } 1
$$

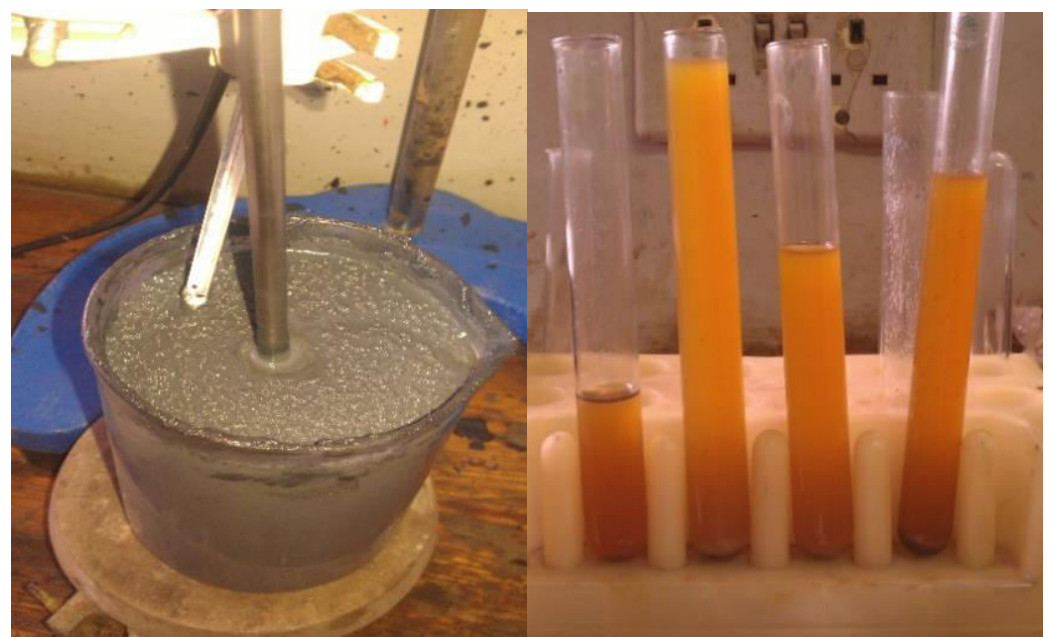

Figure 2, Thick sludge mixture with $\mathrm{KOH}$ on the right and recovered oil on the left 


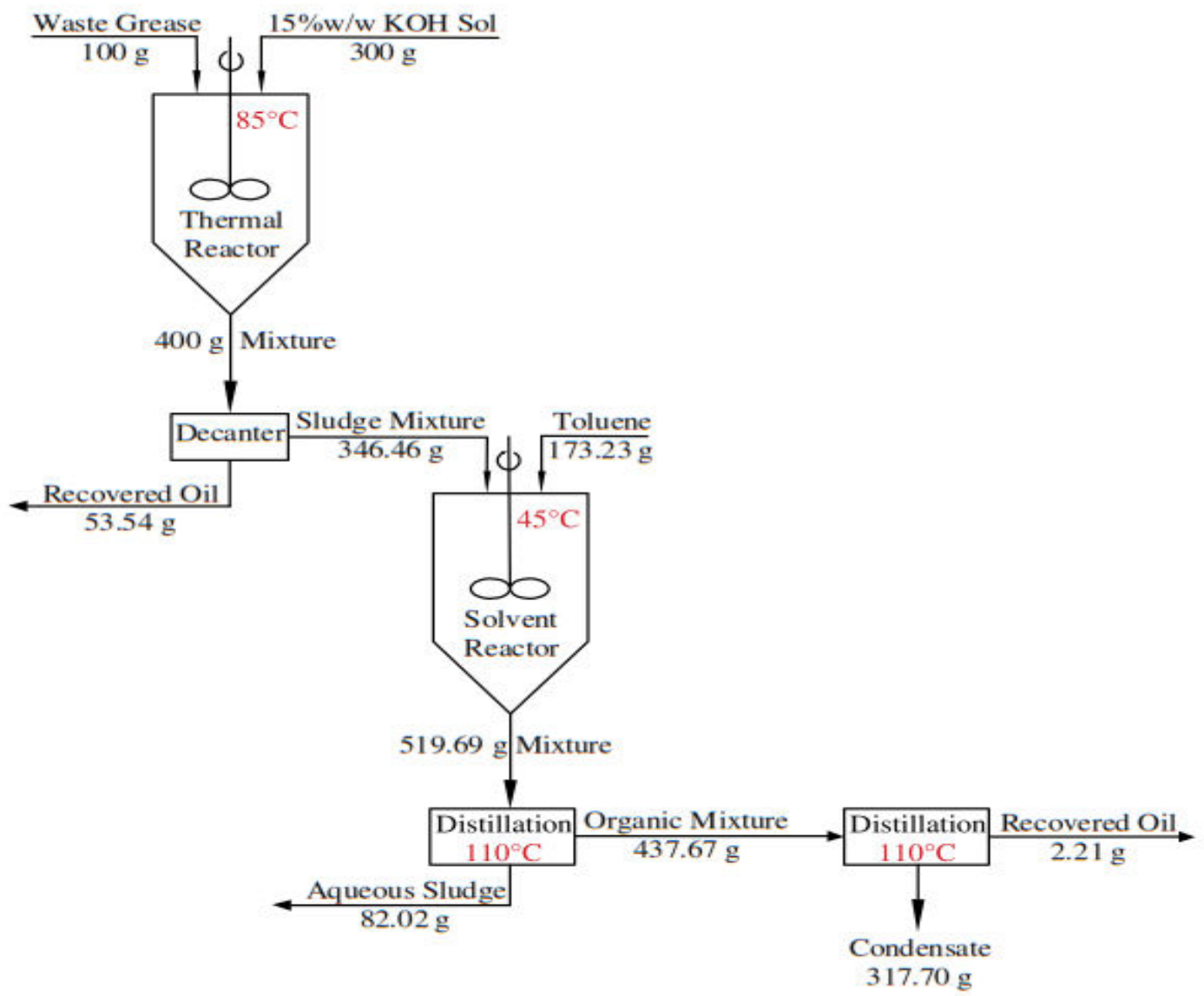

Figure 2, Process flow chart for one of the runs performed [adopted from reference 11]

The calorific value of the recovered oil was also determined using the Bomb calorimeter. Specific gravity of the recovered base oil was also determined at $15^{\circ} \mathrm{c}$ using ASTMD 1298 method. Viscosity of the oil was also determined using the ASTMD 445 method. Water content was determined using ASTMD 95 test method.

Elemental analysis of the recovered base oil using Emission Spectrometry to determine Silicon, Copper, Chromium, Aluminium, Iron, Lead and Tin was conducted using ECM 05 method.

\section{Results and Discussion}

The waste grease that was used was black and thick in colour. The results from the investigation are shown in table 1. Several trials under the same conditions were performed using $\mathrm{KOH}$ and Toulene. $\mathrm{KOH}$ was used as it can easily penetrate the grease matrix [9]. The highest recovered oil recorded was $75.35 \%$. It was observed that some of the material was lost during the experiament due to its adhesiveness to the glassware. Similar extraction yields were observed by a study conducted by [7,]. Reference 11, achieved the highest recovery of $75 \%$. The percent removal of base oil from the waste grease indicates a reduced volume of waste grease which could be an added advantage especially at hazardous storage facilities. 
Toulene was added to the sluge mixture generated after the first recovey of the base oil as it offered good solubility and anti-solvent effects for non polar or slightly polar polymeric additives, metals and carbonaceous particles [9]. Low amounts of oil was recovered after addition of Toulene as most of it was recovered in the first instance.

Table 2, Amount of recovered base oil from waste grease

\begin{tabular}{l|llll}
\hline \multirow{2}{*}{$\begin{array}{l}\text { Weight of Grease } \\
\text { used [g] }\end{array}$} & $\begin{array}{l}\text { RECOVERED OIL } \\
\text { recovered after } \\
\text { addition of } \\
\text { KOH [g] }\end{array}$ & $\begin{array}{l}\text { Base oil recoverd } \\
\text { after addition of } \\
\text { Toulene [g] }\end{array}$ & $\begin{array}{l}\text { Total Base Oil } \\
\text { Recoverd [g] }\end{array}$ & $\begin{array}{l}\text { \% Base Oil } \\
\text { Recovery }\end{array}$ \\
\hline 100 & 60.97 & 10.37 & 71.34 & 71.34 \\
100 & 37.37 & 29.63 & 67.00 & 67.0 \\
100 & 36.23 & 20.17 & 56.40 & 56.40 \\
100 & 49.05 & 17.88 & 66.93 & 66.93 \\
100 & 53.54 & 2.21 & 55.75 & 55.75 \\
\hline
\end{tabular}

Properties of oil recovered in this investigation is shown in table 2. Properties of Diesel and oil used at one of the smelters in the mines were compared to that of the recovered oil. The calorific value of the recovered oil was found to be high though $13.84 \mathrm{MJ} / \mathrm{kg}$ less than that of diesel. Sulphur content of the oil was $0.41 \mathrm{ppm}$ far much less than that of diesel and smelter oil. The moisture content of the base oil was found to be $96 \%$ higher than that of both diesel and smelter oil. Based on the high calorific values and similar results conducted by [10,11], the recovered oil could be used as an alternative fuel or as a second grade fuel for diesel oil. However, excessive water in the base oil would hinder the performance if used in this way hence require further treatment to remove the moisture.

Viscosity is a very important property indicating resistance to flow and related to temperature, pressure and film formation [12]. High visicosity indicates high resistance to flow and low viscosity implies low resistance to flow [12].

Table 2, Properties of recovered base oil in comparision to diesel and smelter oil

\begin{tabular}{llll}
\hline Property & Base oil & Diesel & Smelter oil \\
\hline Density [kg/m $\mathbf{m}^{\mathbf{3}}$ ] & 947 & 800 & 850 \\
Viscosity at $\mathbf{4 0}^{\circ} \mathbf{c}[\mathbf{c s t}]$ & 4.43 & $2.2-5.3$ & $2.2-5.3$ \\
Calorific value & 32.26 & 46.1 & 42 \\
[MJ/kg] & & 500 & 750 \\
Sulphur [ppm] & 0.41 & 0.05 & 0.05 \\
Water content [\%] & 1.40 & & \\
\hline
\end{tabular}

Thickeners which are stearates of metal soaps like Lithium, Calcuim, Aluminum and Titanium forms the fiber structures which immobilise the base oil in the lubricating grease [13]. Dirt and wear analysis was done through the determination of elements in the recovered oil using Emission Spectrometry. Silicon, Copper, Chromium, Aluminium, Iron, Lead and Tin were analysed as shown in table 3. 
Table 3, Elements in the recovered oil

\begin{tabular}{l|l}
\hline Element & Concentration [ppm] \\
\hline Silicon & 42.08 \\
Iron & 23.31 \\
Copper & 3.24 \\
Aluminium & 21.74 \\
Lead & 0.1 \\
Tin & 0
\end{tabular}

Silicon (dirt) was the highest amount in the oil. Concentration of $23.31 \mathrm{ppm}$ and $21.74 \mathrm{ppm}$ of iron and aluminium was found in the oil. This is an indication of mechanical wear and corrosion [10].

\section{Conclusion}

Waste oil generation will continue in process industry and mines. It is important thet methods of treatment are investigated. Base oil was recovered from waste grease using $\mathrm{KOH}$ and Toulene. This provides for the treatment of lubricant grease and hence reduce on the environmental pollution burden that is created during its disposal.

\section{References}

[1] A.M. Siti Kholijah, S.L. Cheryl Yeuag, S. Sazuani and R.M. Yunus, Production of high temperature grease from waste lubricant sludge and silicone oil, Journal of Applied Sciences, $12,1171-1175 \mathrm{P}$

[2] J. Rincon, P. Canizares, M.T. Garcia, Regeneration of used Lubricant Oil by Polar Solvent Extraction. Ind. Eng. Chem. Res. vol. 44, pp. 4373 - 4379, (2005)

[3] J.M. Diphare, J. Pilusa, E. Muzenda, A review of waste lubricating grease management. 2nd International Conference on Environment, Agriculture and Food Science, Kuala Lumpur Malaysia, August 25 - 26 (2013)

[4] J. M. Diphare, J. Pilusa, E. Muzenda, The effect of degrading agents and diluents on oil recovery from Lithium based waste lubricating grease. 2nd International Conference on Environment, Agriculture and Food Science, Kuala Lumpur, Malaysia, August 25 - 26 (2013)

[5] R. Musemić and A. Basić, The waste oil influence and risks on the environment in refer to Bosnia and Herzegovina, $15^{\text {th }}$ International Research/ Expert Conference, Prague, Czech Republic, pp. $12-18,2011$ 
[6] M. Alves dos Reis, J.M. Silva, Waste lubricating oil Re- refining by extraction- flocculation. 2. A method to formulate efficient composite solvents. Ind.Eng.Chem. Res., vol 29, pp. 432 432, (1990).

[7] M. Diphare, E. Muzenda. The effect of extraction conditions on oil yield from waste lubricating grease. International Journal of Research in Chemical, Mechanical and Civil Engineering, vol, 1 , issue 1 (2014)

[8] Y. L. Hsu, C.H. Lee, W.B. Kreng, Analysis and comparision of regenerative technologies of waste lubricants. Transactions on Environment and Development, Vol. 5 (3), pp. 295 - 309, 2011

[9] M. Diphare and E. Muzenda, Influence of solvent on the extraction of oil from waste lubricating grease, A comparative study, $2^{\text {nd }}$ International conference on agriculture, environment and biological sciences, Pattaya, Thailand, Dec 17 - 18, 2013

[10] M. Diphare and E. Muzenda, Analysis and characterisation of waste lubricating grease derived oil, $2^{\text {nd }}$ International conference on agriculture, environment and biological sciences, Pattaya, Thailand, Dec 17 - 18, 2013

[11]T.J. Pilusa and E. Muzenda, M. Shukla, Thermo-chemical extraction of fuel oil from waste lubricating grease, Waste Management, vol 33, pp 1509 - 1515,2013

[12]H.M. Mobarak, E. Niza Mohamad, H.H. Masjuki, M.A. Kalam, K.A.H. Al Muhmud, M. Habibullah and A.M. Ashraful, The prospects of biolubricants as alternatives in automotive applicantions, Renewable and Sustainable Energy Reviews, 33, pp 34 - 43, 2014

[13] C. Dhiman, M.N. Reddy, K. Gulati and M.S.Khan, Detection of elemental composition of lubricating grease using laser induced breakdown spectrospcopy, Lubricants, 2, pp 233 - 236, 2014 